\title{
Electrical behaviour of arsenic implanted silicon wafers at large tilt angle
}

\author{
G.Claudio, C.Jeynes K.J.Kirkby B.J.Sealy and R. \\ Gwilliam \\ School of Electronics and Physical Sciences \\ University of Surrey Guildford \\ GU2 7XH England UK \\ g.claudio@surrey.ac.uk
}

\author{
R. Low \\ Applied Materials UK Ltd. Parametric and Conductive \\ Division \\ Foundry Lane, Horsham, West Sussex \\ RH13 5PX England UK
}

\begin{abstract}
Two sets of silicon wafers were implanted with $60 \mathrm{keV}$ arsenic ions at a dose of $5 \times 10^{15} \mathrm{~cm}^{-2}$, using an Applied Materials SWIFT implanter. The first batch consisted of five silicon preamorphised wafers, whilst the second batch was implanted under the same conditions into $<100>$ single crystal wafers. The tilt angle was varied over the range $0^{\circ}-45^{\circ}$. After implantation the samples were cut into smaller pieces and annealed in the range 800 to $1000{ }^{\circ} \mathrm{C}$ for times up to 60 seconds in flowing nitrogen. Van der Pauw measurements of the Hall effect and resistivity were made to obtain values of the sheet resistance $\left(R_{S}\right)$, Hall mobility $\left(\mu_{H}\right)$ and sheet carrier concentration $\left(N_{S}\right)$ as a function of the tilt angle. Electrical profiles were obtained from differential Hall effect measurements, whilst the retained dose was determined by Rutherford Back Scattering (RBS). The results show that the sheet resistance and the sheet carrier concentration are a function of the tilt angle and that preamorphisation results in a higher degree of electrical activation. A comparison of atomic and carrier concentration profiles as a function of tilt angle in conjunction with simulations are used to explain the observed results.
\end{abstract}

Keywords-component: tilt angle, Arsenic, RBS, Hall effect

\section{INTRODUCTION}

The ion dose has become a very difficult process to control as the angle between the beam direction and wafer normal increase [1]. High angle implants with a tilt angle from 30 to 60 degrees have became more and more important for implantation under masking structures and doping of nonplanar structures such as trench sidewalls [2].

In order to dope the sidewalls of a trench it is necessary to perform angled ion implantation. In most cases, ion implantation is performed at $7^{\circ}$ tilt in order to avoid channeling [3]. Increasing the tilt angle will move the dopant concentration near to the surface decreasing the junction depth. This affects both the sheet resistivity and the sheet carrier concentration. However it is important to understand how much dopant is retained in the wafers when the angle is changed and how this can effect the electrical properties of the implanted material.
To investigate this effect, arsenic ions have been implanted into crystalline and pre-amorphised wafers to check if the preamorphisation could improve the activation of the dopant and to determine the retained dose as a function of angle of implant.

\section{EXPERIMENTAL}

The first batch of $200 \mathrm{~mm} \mathrm{Si}$ wafers were implanted at tilt angles of $0^{\circ}, 15^{\circ}, 30^{\circ}, 45^{\circ}$ and $0^{\circ}$ twist with a nominal dose of $5 \times 10^{15} \mathrm{As}^{+} \mathrm{cm}^{-2}$ and an energy of $60 \mathrm{keV}$. The second batch was pre-amorphised using $60 \mathrm{keV} \mathrm{Ge}{ }^{+}$with a dose of $1 \times 10^{15}$ $\mathrm{at} / \mathrm{cm}^{2}$ prior to the arsenic implant. After implantation the samples were annealed in a Process Product Corporation RTP halogen lamp system.

The annealing was performed in nitrogen ambient in the range 800 to $1000{ }^{\circ} \mathrm{C}$ for times of up to 60 seconds. Each wafer was cut into pieces for RBS Hall effect and resistivity measurements. Clover leaf shapes were made on the samples using a photolithography technique for van der Pauw measurements of the Hall effect and resistivity in order to obtain values of the sheet resistance $\left(\mathrm{R}_{\mathrm{S}}\right)$, Hall mobility $\left(\mu_{\mathrm{H}}\right)$ and sheet carrier concentration $\left(\mathrm{N}_{\mathrm{S}}\right)$ as a function of the tilt angle. Electrical profiles were obtained from differential Hall effect measurements, whilst the retained dose was determined by Rutherford Back Scattering (RBS) analyses using $1.5 \mathrm{MeV}$ ${ }^{4} \mathrm{He}^{+}$ions.

\section{RESULTS AND DISCUSSION}

\section{A. RBS measurements}

RBS analysis was performed on the two sets of samples. The first set of measurements were to estimate the retained dose on as-implanted samples, whilst the second set of measurements was performed on samples after annealing to determine the retained dose. 
TABLE I. RETAINED DOSE MEASURED BY RBS FOR ALL THE WAFERS AT DIFFERENT TILT ANGLE BEFORE ANNEALING

\begin{tabular}{|c|c|c|c|c|}
\hline \hline $\begin{array}{c}\text { Tilt } \\
\text { angle } \\
\text { (degrees) }\end{array}$ & $\begin{array}{c}\text { Nominal } \\
\text { dose } \\
(\mathbf{1 0} \\
\left.\mathbf{1 5} / \mathbf{c m}^{\mathbf{2}}\right)\end{array}$ & $\begin{array}{c}\text { Retained } \\
\text { dose } \\
\mathbf{( 1 0}^{\mathbf{1 5}} \\
\left.\mathbf{a t} / \mathbf{c m}^{\mathbf{2}}\right)\end{array}$ & $\begin{array}{c}\text { Pre- } \\
\text { amorphised }\end{array}$ & Crystalline \\
\hline \hline 0 & 5.00 & 4.96 & Yes & \\
\hline 15 & 5.00 & 4.97 & Yes & \\
\hline 30 & 5.00 & 4.95 & Yes & \\
\hline 45 & 5.00 & 4.98 & Yes & Yes \\
\hline 0 & 5.00 & 4.98 & & Yes \\
\hline 15 & 5.00 & 4.97 & & Yes \\
\hline 30 & 5.00 & 4.96 & & Yes \\
\hline 45 & 5.00 & 4.96 & & \\
\hline
\end{tabular}

TABLE II. RETAINED DOSE MEASURED BY RBS FOR ALL THE WAFERS AT DIFFERENT TILT ANGLE AFTER ANNEALING AT $800^{\circ} \mathrm{C}$

\begin{tabular}{|c|c|c|c|c|}
\hline \hline $\begin{array}{c}\text { Tilt } \\
\text { angle } \\
\text { (degrees) }\end{array}$ & $\begin{array}{c}\text { Nominal } \\
\text { dose } \\
(\mathbf{1 0} \\
\left.\mathbf{1 t} / \mathbf{c m}^{\mathbf{2}}\right)\end{array}$ & $\begin{array}{c}\text { Retained } \\
\text { dose } \\
\mathbf{( 1 0} \\
\left.\mathbf{1 0} / \mathbf{c m}^{\mathbf{2}}\right)\end{array}$ & $\begin{array}{c}\text { Pre- } \\
\text { amorphised }\end{array}$ & Crystalline \\
\hline \hline 0 & 5.00 & 4.46 & Yes & \\
\hline 45 & 5.00 & 4.44 & Yes & \\
\hline 0 & 5.00 & 4.47 & & Yes \\
\hline 45 & 5.00 & 4.45 & & Yes \\
\hline
\end{tabular}

Results in Table I show that for as implanted samples the implanted dose $\left(5 \times 10^{15}\right)$ is equal to the retained dose (average of $4.97 \times 10^{15}$ ), within experimental error. Thus we can deduce that no sputtering or backscattering occurs. From Table II we can deduce that the retained dose has reduced by about $10 \%$ to $4.46 \times 10^{15} \mathrm{~cm}^{-2}$ on average for all the wafers after annealing. This is a consequence of the out-gassing of arsenic during annealing. The absolute error in the retained dose for each single measurement was less than $3 \%$.

\section{B. Electrical results}

The Van der Paw technique was employed to measure the sheet resistance, Hall mobility and the sheet carrier concentration. Figures 1 to 6 show the sheet resistance, sheet electron concentration and Hall mobility as a function of the tilt angle for pre-amorphised and crystalline wafers for different annealing temperatures and times.

At this level of doping for arsenic the junction depth controls the sheet resistivity [4]. So as soon the tilt angle increases the junction depth decreases and the decrease in junction depth results in a higher sheet resistivity [5].
The figures show that the mobility is approximately constant with tilt angle and that the sheet resistance tends to increase and the sheet carrier concentration tends to decrease with increasing tilt angle. The three variables, $R_{S}, \mu_{H}$ and $N_{S}$ are linked together by:

$$
\mu_{H}=\frac{1}{q} \frac{1}{R_{S} N_{S}}
$$

where $\mathrm{q}$ is the electronic charge.

Thus the results are consistent in that we find that $R_{s}$ is inversely proportional to $\mathrm{n}_{\mathrm{s}}$, with constant mobility.

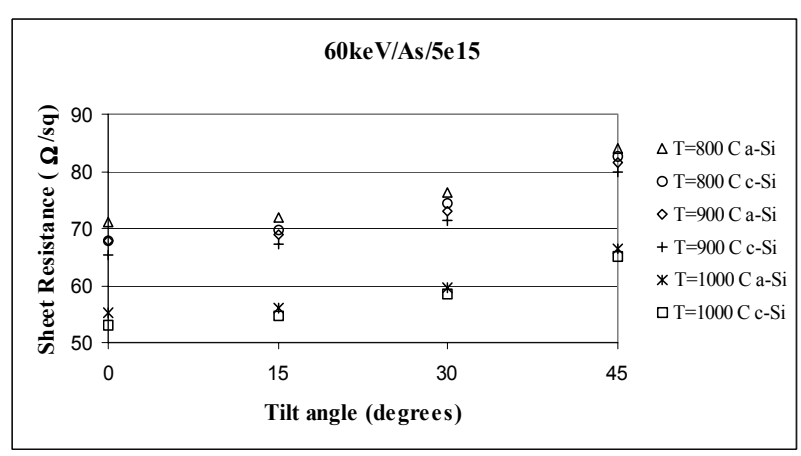

Figure 1. Sheet resistance as a function of the tilt angle for $60 \mathrm{keV} \mathrm{As}^{+}$at different annealing temperatures for time of annealing of $30 \mathrm{sec}$

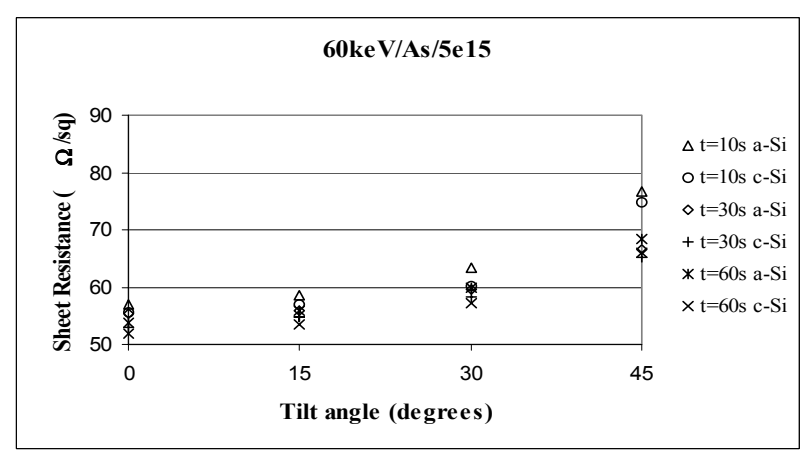

Figure 2. Sheet resistance as a function of the tilt angle for $60 \mathrm{keV} \mathrm{As}{ }^{+}$at different annealing times for a temperature of annealing of $1000^{\circ} \mathrm{C}$ 


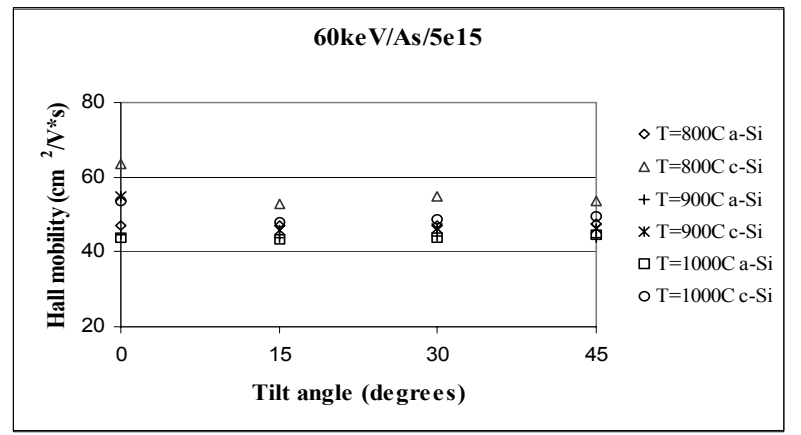

Figure 3. Hall mobility as a function of the tilt angle for $60 \mathrm{keV} \mathrm{As}^{+}$at different annealing temperatures

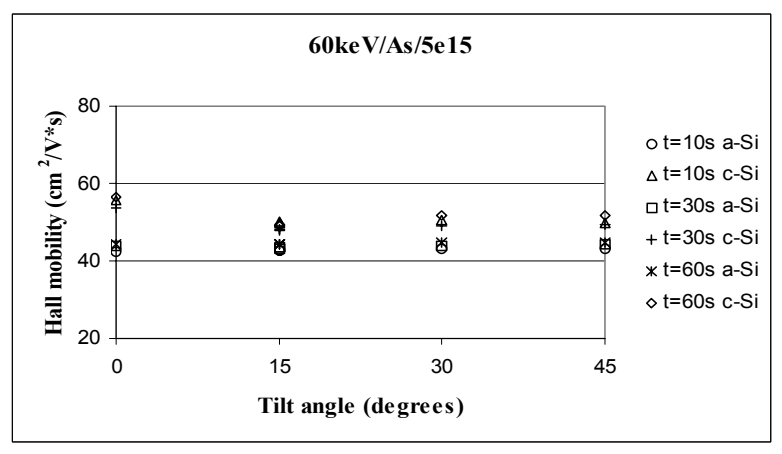

Figure 4. Hall mobility as a function of the tilt angle for $60 \mathrm{keV} \mathrm{As}^{+}$at different annealing times

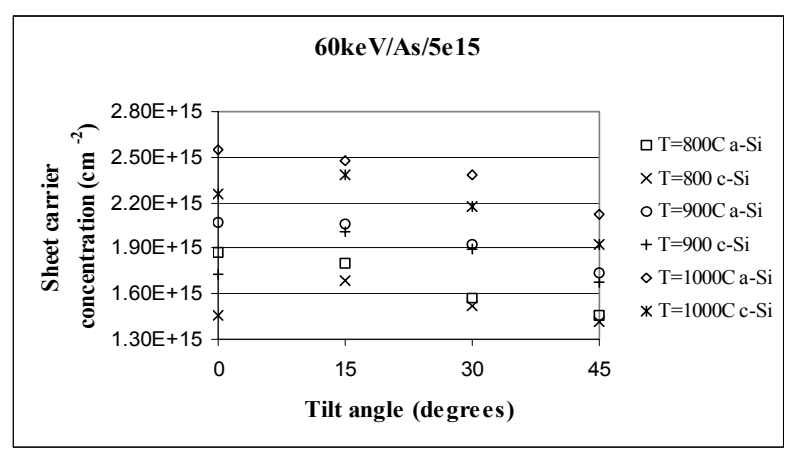

Figure 5. Sheet carrier concentration as a function of the tilt angle for 60 $\mathrm{keV} \mathrm{As}^{+}$at different annealing temperatures

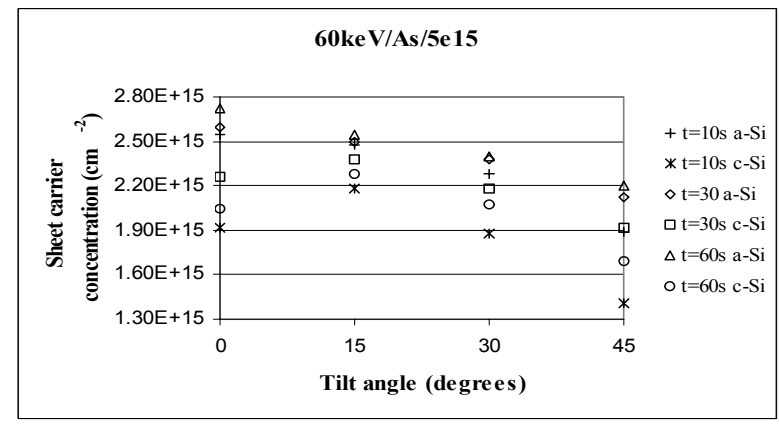

Figure 6. Sheet carrier concentration as a function of the tilt angle for 60 $\mathrm{keV} \mathrm{As}^{+}$at different annealing times

From figures 5 and 6 we can observe that samples which have been pre-amorphised with germanium have shown a better activation for all the annealing temperatures and times. Pre-amorphisation with germanium also results in a shallower junction depth and a better electrical activation [6].

\section{Differential Hall Measurements (DHM)}

Simulations (using MonteCarlo code) [7] of the atomic profile after annealing were compared with DHM measurements performed to estimate the amount of electrically active dopant in the silicon.

The DHM measurements give us the distribution of the active dopant as a function of depth. The area under the curve is equal to the fraction of the retained dose that is electrically activated. Table III summarises the results. The "Hall" data refer to the sheet carrier concentration as a fraction of the retained dose after annealing, whilst the "DHM" data refer to the integrated area beneath the electrical profile of figure 7 . The magnitude of these two parameters is very similar showing the consistency of the data and measurement techniques. The Silvaco simulations of the electrical activity (Table III) overestimate the electrical activity especially at high tilt angles. We note from fig. 7 that only a fraction of the retained arsenic is active after annealing because at high doses arsenic tends to form precipitates [8].

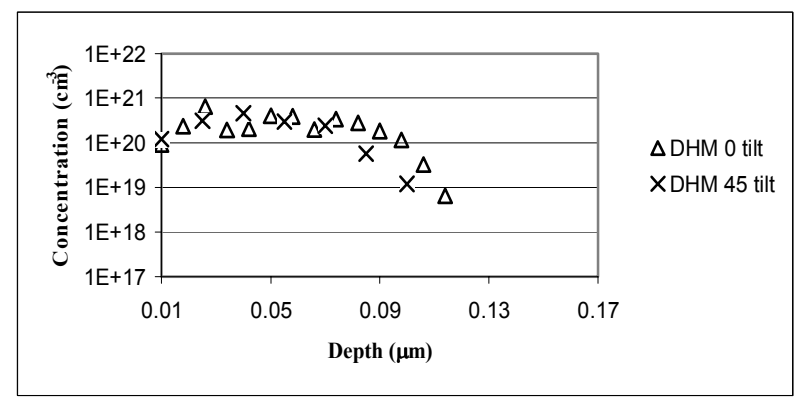

Figure 7. Carrier concentration profiles of $60 \mathrm{keV}$ As at $0^{\circ}$ and $45^{\circ}$ tilt; dose $5 \times 10^{15} \mathrm{~cm}^{-2}$ after annealing for $30 \mathrm{sec}$ at $1000^{\circ} \mathrm{C}$ 


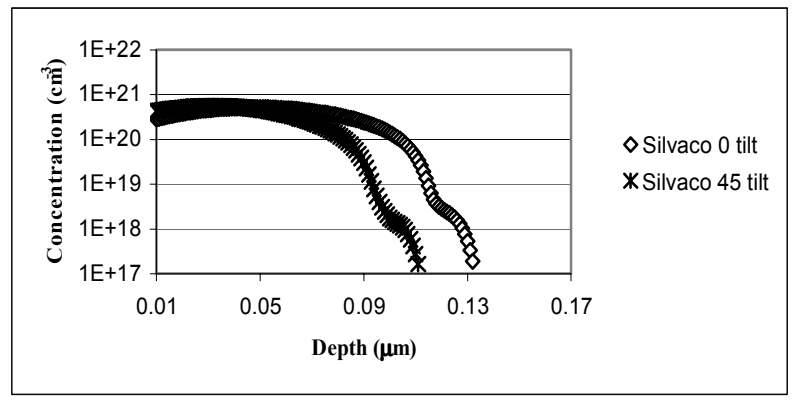

Figure 8. Silvaco simulation of $60 \mathrm{keV}$ As at $0^{\circ}$ and $45^{\circ}$ tilt; dose $5 \times 10^{15} \mathrm{~cm}^{-}$ ${ }^{2}$ after annealing for $30 \mathrm{sec}$ at $1000^{\circ} \mathrm{C}$

TABLE III. ACTIVAVATION OF IMPLANTED DOPANT WITH DIFFERENT TECHNIQUES FOR $60 \mathrm{KEV} \mathrm{AS}{ }^{+}$AFTER ANNEALING AT $1000^{\circ} \mathrm{C}$ FOR $30 \mathrm{SEC}$

\begin{tabular}{|c|c|c|c|c|}
\hline \hline $\begin{array}{c}\text { Tilt } \\
\text { angle } \\
\text { (degrees) }\end{array}$ & $\begin{array}{c}\text { Hall } \\
(\mathbf{\%})\end{array}$ & $\begin{array}{c}\text { DHM } \\
(\mathbf{\%})\end{array}$ & $\begin{array}{c}\text { Silvaco } \\
\mathbf{( \% )}\end{array}$ & $\begin{array}{c}\text { Pre- } \\
\text { amorphised }\end{array}$ \\
\hline \hline 0 & 56.7 & 58.2 & 73.4 & Yes \\
\hline 45 & 47.1 & 48.0 & 67.6 & Yes \\
\hline 0 & 50.2 & 49.8 & 82.0 & No \\
\hline 45 & 40.2 & 41.1 & 58.0 & No \\
\hline
\end{tabular}

\section{CONCLUSION}

The sheet resistance and sheet carrier concentration as a function of the tilt angle have been investigated. It was found that they are a function of the tilt angle. Thus for high tilt angle the sheet resistance increases and the concentration of activated dopant decreases. At the same time the Hall mobility remains approximately constant for all the tilt angles. By comparing implantation into pre-amorphised and crystalline wafers it was found that wafers pre-amorphised with germanium show a higher activation compared to crystalline wafers.

\section{REFERENCES}

[1] M.I. Current L.Larson, W.A. Keenan and C.B. Yarling "Proccess control for Ion Implantation" Handbook of Ion Implantation Technology ed. By J.F.Ziegler (1992)

[2] S.Wolf, Silicon Processing for the VLSI Era Volume 2: Process integration (Lattice, Sunset Beach, CA, 1990), p. 600.

[3] C.Russo Rapid thermal processing-Where has it been? Where is it going? Nucl. Instr. and Meth. B6 (1985) pp.298-306

[4] M.Kase, K. Okabe, T.Kubo, M. Saitoh, N.tamura, and H.Mori FEOL technology for fabricating high performance logic and system LSI of $100 \mathrm{~nm}$ node IIT 2000 Proceeding pp. .91-94

[5] P.J.Mole Electron Mobility in bulk Si "Properties of Silicon" INSPEC n.4 (1987) 123-127

[6] J.Liu and S.Mehta Mat. Res. Soc. Symp. Vol.610 (2000) B4.6.1-6

[7] SSUPREM-4 User's manual, Silvaco Intern. (1997)

[8] M.A. Sahinerand, S.W. Novak, J. Woicic, J. Liu V. Krishnamoorthy Arsenic clustering and precipitation analysis in ion-implanted Si wafers by X-ray absorption spectroscopy and SIMS IIT2000 proceedings 600603 